\title{
ПРАВОВЫЕ И ТЕХНОЛОГИЧЕСКИЕ ОСОБЕННОСТИ РЕАЛИЗАЦИИ «ДАЧНОЙ АМНИСТИИ»
}

\section{Татьяна Николаевна Шарапова}

Сибирский государственный университет геосистем и технологий, 630108, Россия, г. Новосибирск, ул. Плахотного, 10, обучающийся, тел. (913)767-57-99, e-mail: kuznetsovatanya_777@inbox.ru

\section{Наталья Олеговна Митрофанова}

Сибирский государственный университет геосистем и технологий, 630108, Россия, г. Новосибирск, ул. Плахотного, 10, кандидат технических наук, доцент кафедры кадастра и территориального планирования, тел. (923)137-18-88, e-mail: north-easter@yandex.ru

\section{Владимир Игоревич Норкин}

Сибирский государственный университет геосистем и технологий, 630108, Россия, г. Новосибирск, ул. Плахотного, 10, соискатель, тел. (913)703-86-86, e-mail: norkin@innsk.org

Актуальность данной темы обусловлена активной реализацией граждан возможности упрощенного порядка кадастрового учета и регистрации прав на отдельные виды объектов недвижимости. Данный порядок имеет свои отличительные особенности от стандартной процедуры и оснований для кадастрового учета и регистрации прав.

В данной работе описывается процедура упрощенного порядка государственного кадастрового учета и государственной регистрации прав граждан на объекты недвижимости в рамках «дачной амнистии», существующие проблемы и результаты реализации «дачной амнистии».

Ключевые слова: дачная амнистия, технический план, земельные участки, кадастровые работы, государственный кадастровый учет, государственная регистрация прав, границы, населенные пункты, единый государственный реестр недвижимости

\section{LEGAL AND TECHNOLOGICAL FEATURES OF REALIZATION OF «COTTAGE AMNESTY»}

\section{Tatyana N. Sharapova}

Siberian State University of Geosystems and Technologies, 10, Plakhotnogo St., Novosibirsk, 630108, Russia, Student, phone: (913)767-57-99, e-mail: kuznetsovatanya_777@inbox.ru

\section{Natalia O. Mitrofanova}

Siberian State University of Geosystems and Technologies, 10, Plakhotnogo St., Novosibirsk, 630108, Russia, Ph. D., Assoc. Prof., Department of Cadastre and Territorial Planning, phone: (923)137-18-88, e-mail: kadastr-204@yandex.ru

\section{Vladimir I. Norkin}

Siberian State University of Geosystems and Technologies, 10, Plakhotnogo St., Novosibirsk, 630108, Russia, Ph. D. Student, phone: (913)703-86-86, e-mail: norkin@innsk.org

The relevance of this topic is due to the active implementation of citizens of the possibility of a simplified procedure for cadastral registration and registration of rights to certain types of real estate objects. This procedure has its own distinctive features from the standard procedure and grounds for cadastral registration and registration of rights. This paper describes the procedure for a simplified 
procedure for state cadastral registration and state registration of citizens' rights to real estate objects within the framework of the "dacha amnesty", the existing problems and the results of the implementation of the "dacha amnesty".

Keywords: dacha amnesty, technical plan, land plot, cadastral work, state cadastral registration, state registration of rights, borders, settlements, Unified State Register of Real Estate

Актуальность выбранной темы обуславливается реализацией в настоящее время очередного этапа проведения так называемой «дачной амнистии».

Дачная амнистия - это народное название различных законов, которые позволяют в упрощенном порядке регистрировать некоторые объекты недвижимости.

Дачная амнистия впервые была запущена Федеральным законом от 30.06.2006 г. № 93-Ф3 «О внесении изменений в некоторые законодательные акты Российской Федерации по вопросу оформления в упрощенном порядке прав граждан на отдельные объекты недвижимого имущества» [4]. Именно после введения в действие этого закона, а именно с 1 сентября 2006 года, возникло такое понятие. Основная задача, которую выполнял механизм - вывести из теневого оборота земельные участки и вовлечь их в систему налогообложения.

Любые нововведения в данном направлении сконцентрированы в первую очередь на разрешении проблем отсутствия у граждан документов на принадлежащие им объекты недвижимости, ведь количество неузаконенного строительства в России является колоссальным, и в ряде случаев, недвижимость не регистрируют преднамеренно, чтобы избежать уплаты налогов [8]. Однако, право собственности на незарегистрированное недвижимое имущество является законодательно не удостоверенным, стало быть, и совершение сделок с таким имуществом невозможно, так как подобная сделка не будет иметь юридической силы. До принятия закона «о дачной амнистии» граждане могли защитить свои субъективные права или разрешить спор только в судебном порядке.

Такой механизм как «дачная амнистия» играет важную роль в формировании современной системы кадастрового учета и регистрации прав.

Так как «дачной амнистией» считается целый ряд законов, то и сроки этих законов разные. Поэтому нет такого понятия как срок дачной амнистии. Одна статья закона считается бессрочной, вторая продлена до определенного срока, третья уже не действует.

Далее рассмотрим виды объектов недвижимости, которые можно оформить в упрощенном порядке по дачной амнистии:

1. Земельные участки, которые выдавались гражданам до 30 октября 2001 года в постоянное (бессрочное) пользование или пожизненное наследуемое владение для ведения личного подсобного хозяйства, дачного хозяйства, огородничества, садоводства, индивидуального гаражного или жилищного строительства. Данное упрощение бессрочно [6].

Чтобы оформить такой земельный участок в собственность не нужно выкупать его у государства. Участки передаются в собственность бесплатно. 
Процедура государственного кадастрового учета предполагала внесение сведений о земельных участках без проведения межевания. Сведения о ранее учтенных земельных участках могут вноситься в ЕГРН на основании правоустанавливающих, правоудостоверяющих документов или документов, подтверждающих учет земельных участков. В основном такие документы не содержат каких-либо сведений о местоположении границ земельного участка. Поэтому такие земельные участки не могут быть однозначно идентифицированы в ЕГРН, что в свою очередь не обеспечивает правообладателей гарантией соблюдения их прав в отношении таких земельных участков [7].

С 1.03.2015 года вступили в силу поправки в Земельный кодекс Российской Федерации в части образования и предоставления земельных участков, находящихся в государственной или муниципальной собственности. Образование осуществляется в соответствии с одним из следующих документов:

- проект межевания территории, утвержденный в соответствии с Градостроительным кодексом РФ;

- проектная документация о местоположении, границах, площади и об иных количественных и качественных характеристиках лесных участков;

- утвержденная схема расположения земельного участка или земельных участков на кадастровом плане территории.

Таким образом, с 2015 года внесение участок в ЕГРН без предварительного межевания стало невозможным.

2. Садовые/жилые дома и хозяйственные постройки, расположенные на земельных участках, предназначенных для ведения гражданами садоводства. Такие дома регистрируются по упрощенной схеме на основании декларации, технического плана и правоустанавливающего документа на земельный участок.

После окончания первого этапа дачной амнистии с 1 марта 2019 года, помимо перечисленных документов, необходимо было получать уведомления о начале и об окончании строительства. С 4 августа 2019 года дачная амнистия была продлена с момента вступления в силу Федерального закона от 02.08.2019 № 267-Ф3 до 1 марта 2021 года [5]. После этой даты потребуется вновь уведомлять администрацию о начале и конце строительства - п. 11.1 ст. 24 Федерального закона от 13.07.2015 № 218-Ф3 [3].

На рис. 1 представлен порядок регистрации объектов недвижимости, расположенных на земельных участках, предназначенных для ведения гражданами садоводства.

Недостатком данного упрощения является то, что садовые и жилые дома, расположенные на садовых земельных участках, можно поставить на кадастровый учет без соблюдения градостроительных регламентов. Минимальные отступы, установленные правилами, мало кто соблюдает. Росреестр при оформлении недвижимости довольно лояльно относится к несоблюдению границ, более того, эти границы, как правило, никто не проверяет [10]. 


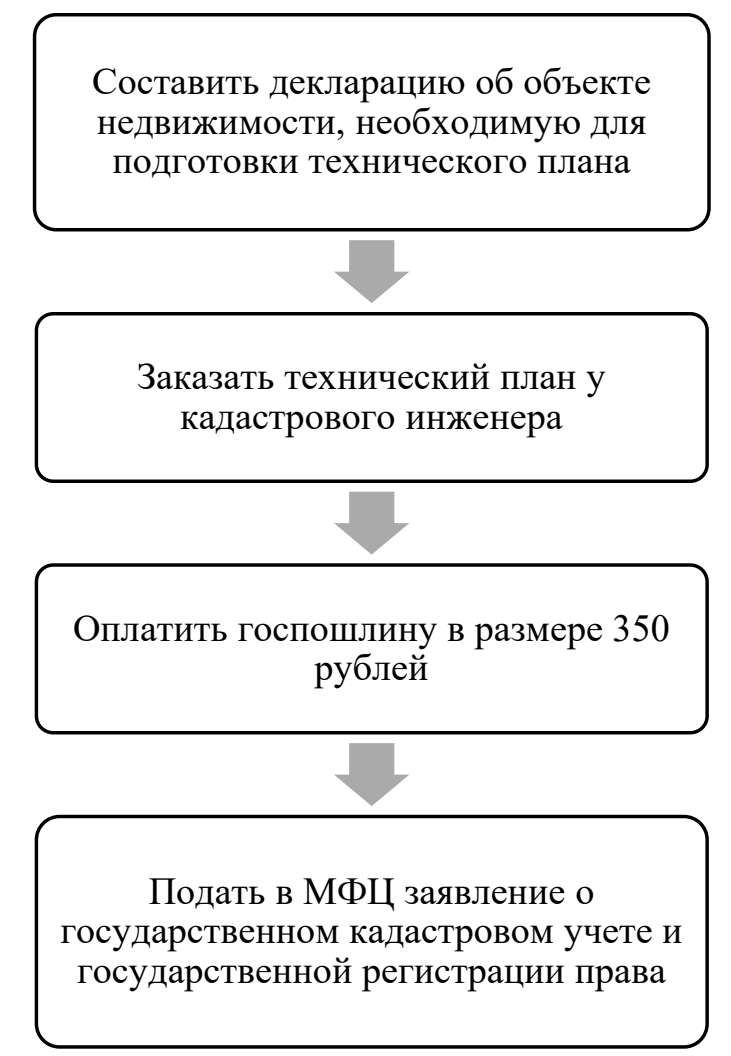

Рис. 1. Схема регистрации объектов недвижимости на земельных участках, предназначенных для ведения садоводства

В данном случае работает принцип «не навреди», так как большинство домов, оформляемых по «дачной амнистии» были построены до введения в действие градостроительных регламентов в РФ, а также ввиду маленьких площадей предоставляемых земельных участков гражданам для ведения садоводства в советское время (в среднем величина участка составляла от 4 до 6 соток).

Сложнее будут обстоять дела после завершения дачной амнистии. Исходя из практики подачи уведомления о начале и завершении строительства садового дома, построенного до 2018 года, органы местного самоуправления будут отказывать заявителю, ввиду несоответствия года постройки. Единственным способом узаконить постройки для заявителя станет судебный порядок. На рис. 2 представлено пересечение красной линии объектом капитального строительства, расположенным на садовом земельном участке в СНТ «Золотая горка» (Новосибирская область).

3. Объект индивидуального жилищного строительства (ИЖС), созданный на земельном участке, который предназначен для индивидуального жилищного строительства или для ведения личного подсобного хозяйства.

4. Строительство объектов ИЖС осуществляется по согласованию с органом государственной власти или местного самоуправления. На рис. 3 представлен порядок регистрации таких объектов. 
54:35:011495:11

обл. Новосибирская, г. Новосибирск, СНТ "Золотая

горка", участок Г-80

План зу $\rightarrow$ План КK $\rightarrow$ Поиск в границах объекта $\rightarrow$

\begin{tabular}{|c|c|}
\hline Информация & Услуги \\
\hline Вид: & Земельный участок \\
\hline Кад. номер: & 54:35:011495:11 \\
\hline Кад. квартал: & $54: 35: 011495$ \\
\hline Статус: & Учтенный \\
\hline Адрес: & $\begin{array}{l}\text { обл. Новосибирская, г. Новосибирск, СНТ } \\
\text { "Золотая горка", участок Г-80 }\end{array}$ \\
\hline Категория земель: & Земли населённых пунктов \\
\hline $\begin{array}{l}\text { Форма } \\
\text { собственности: }\end{array}$ & - \\
\hline $\begin{array}{l}\text { Кадастровая } \\
\text { стоимость: }\end{array}$ & 73843,00 py 6. \\
\hline $\begin{array}{l}\text { Уточненная } \\
\text { площадь: }\end{array}$ & 700 KB. M \\
\hline $\begin{array}{l}\text { Разрешенное } \\
\text { использование: }\end{array}$ & $\begin{array}{l}\text { Для ведения гражданами садоводства и } \\
\text { огородничества }\end{array}$ \\
\hline по документу: & садовые земельные участки \\
\hline
\end{tabular}

Условные обозначения

$\square$ Красные линии

$\square$ Объекты капитального

строительства

Земельные участки

Единицы кадастрового деления

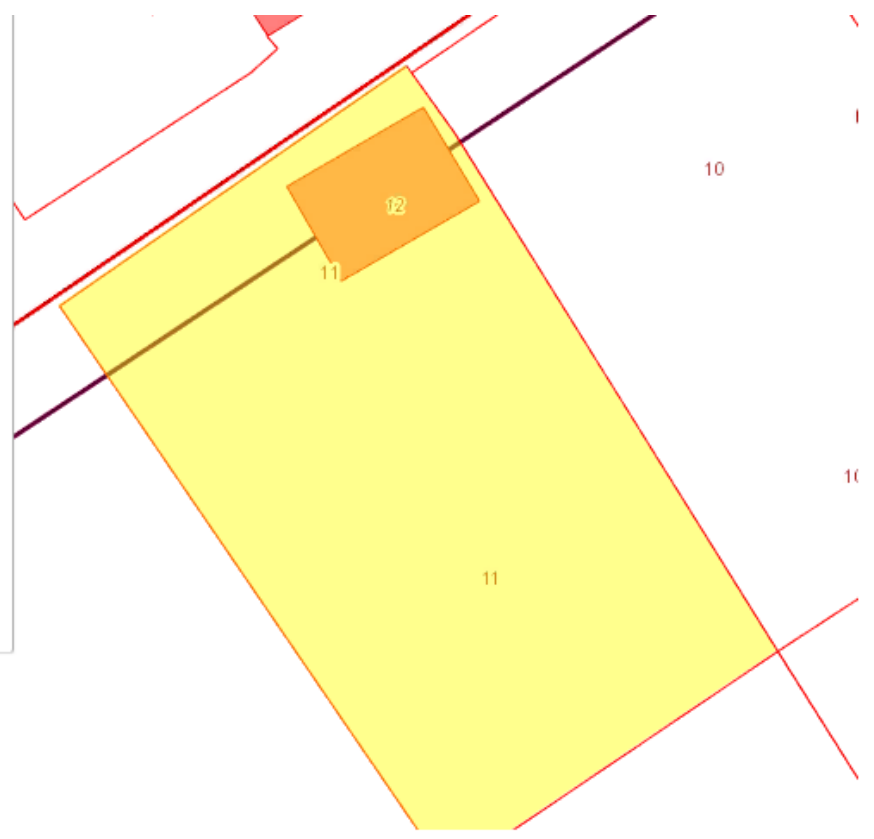

Рис. 2. Выступ объекта капитального строительства за красную линию

Направить уведомление о начале строительства

Получить уведомление о соответствии дома установленным требованиям

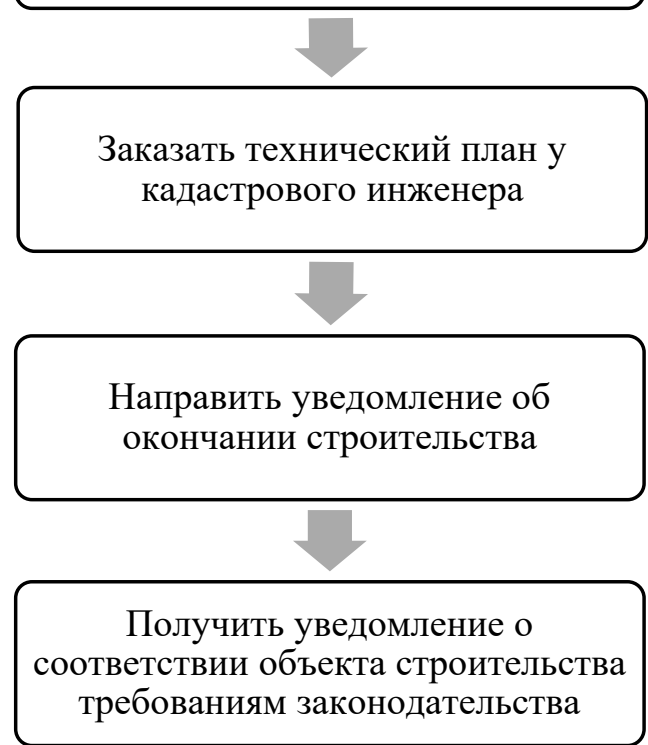

Рис. 3. Порядок регистрации объектов индивидуального жилищного строительства 
В орган местного самоуправления, уполномоченный на выдачу разрешений, до начала строительства застройщик направляет уведомление о планируемом строительстве В течение семи рабочих дней уполномоченный орган должен рассмотреть представленные документы и направить застройщику уведомление о соответствии объекта ИЖС установленным параметрам и допустимости размещения такого объекта на земельном участке либо уведомление о несоответствии. Выданное ранее разрешение на строительство, срок которого не закончился, является так же основанием для подготовки технического плана здания, подавать повторно уведомление не требуется.

Полученное уведомление о соответствии либо несвоевременное направление уполномоченным органом в предусмотренные сроки уведомления о несоответствии считается согласованием и дает застройщику право осуществлять строительство в соответствии с указанными параметрами в течение десяти лет. Указанное право сохраняется при переходе прав на земельный участок и объект недвижимости (ч. 7, 13 ст. 51.1 ГрК РФ).

Кадастровый учет и регистрация права собственности на построенный жилой осуществляются по заявлению уполномоченного органа.

Для этого не позднее месяца со дня окончания строительства необходимо направить в указанный орган уведомление об окончании строительства и иные необходимые документы, в частности технический план построенного объекта недвижимости и соглашение об определении долей на него, заключенное между правообладателями земельного участка, находящегося в долевой собственности [1]. Также необходимо оплатить госпошлину за регистрацию права собственности $[1,3]$.

Выполнив анализ практики реализации дачной амнистии, можно сказать, что новый этап стал непростым продолжением упрощенной процедуры регистрации домов, которая действовала в России последние 13 лет. В упрощенном порядке теперь регистрируются дома и сооружения, расположенные на садовом земельном участке. Объекты капитального строительства, расположенные на землях под индивидуальное жилищное строительство, амнистии больше не подлежат, так как теперь требуется получать в администрации уведомление о соответствии объекта капитального строительства требованиям законодательства.

Вывод: за время действия дачной амнистии граждане смогли оформить и узаконить свое имущество на участках, предоставленных для садоводства, ведения личного подсобного хозяйства и осуществления индивидуального жилищного строительства. Вместе с тем, включение в процедуру оформления кадастрового инженера, с одной стороны позволяет наполнять ЕГРН более полной и достоверной информацией о об объектах, а с другой стороны оформление собственности для гражданина значительно повышается в цене. Также необходимо отметить, что способ оформления прав в текущей редакции закона является оптимальным с технической точки зрения, поскольку подачу заявления и документов можно осуществлять в электронном виде. 


\section{БИБЛИОГРАФИЧЕСКИЙ СПИСОК}

1. Градостроительный кодекс Российской Федерации от 29.12.2004 № 190-Ф3 [Электронный ресурс]: - Доступ из справ.-правовой системы «КонсультантПлюс».

2. Налоговый кодекс Российской Федерации часть 2 от 05.08.2000 № 117-Ф3 [Электронный ресурс]: - Доступ из справ.-правовой системы «КонсультантПлюс».

3. О государственной регистрации недвижимости от 13.07.2015 № 218-Ф3 [Электронный pecypc]: федер. закон. - Доступ из справ.-правовой системы «КонсультантПлюс».

4. О внесении изменений в некоторые законодательные акты Российской Федерации по вопросу оформления в упрощенном порядке прав граждан на отдельные объекты недвижимого имущества от 30.06.2006 № 93-Ф3 [Электронный ресурс]: федер. закон. - Доступ из справ.-правовой системы «КонсультантПлюс».

5. О внесении изменений в отдельные законодательные акты Российской Федерации от 02.08.2019 № 267-ФЗ [Электронный ресурс]: федер. закон. - Доступ из справ.-правовой системы «КонсультантПлюс».

6. О введении в действие Земельного кодекса Российской Федерации" от 25.10.2001 № 137-Ф3 [Электронный ресурс]: федер. закон. - Доступ из справ.-правовой системы «КонсультантПлюс».

7. Разработка методики выполнения комплексных кадастровых работ на территории населенных пунктов [Рукопись] : дис. на соиск. учен. степ. канд. техн. наук по спец. 25.00.26 - Землеустройство, кадастр и мониторинг земель / Н. О. Митрофанова. - Новосибирск : СГУГиТ, 2015. - 115 с.

8. Дачная амнистия: пошаговая инструкция по оформлению [Электронный ресурс]. - Peжим доступа : https://pravoved.ru/journal/dachnaya-amnistiya/.

9. Сайт Федеральной службы государственной регистрации, кадастра и картографии [Электронный ресурс]. - Режим доступа : https://rosreestr.ru/site/press/news/1-marta-2018-godazakanchivaetsya-dachnaya-amnistiya-dlya-individualnykh-zhilykh-domov130218/.

10. Сколько отступать от забора при строительстве дачного дома в 2019 - минимальные отступы от границ земельного участка в СНТ [Электронный ресурс]. - Режим доступа : https://geostart.ru/post/513.

(C) Т. Н. Шарапова, Н. О. Митрофанова, В. И. Норкин, 2021 